\title{
Globalización desde arriba y desde abajo en el Valle de San Quintín, en Oxnard y en otros territorios de producción fresera
}

\section{Globalization from Above and Below in the San Quintin Valley, Oxnard, and Other Strawberry Production Territories}

Anna Mary Garrapa ${ }^{1}$

\section{RESUMEN}

El artículo analizará diferentes métodos de reclutamiento adoptados por empresas locales ubicadas en el Valle de San Quintín, en Baja California, y por compañías transnacionales que operan en el sector fresero en México, así como en EE. UU. Este valle constituye un pasaje fundamental para los migrantes que proceden del sur de México y viajan hacia el norte del país y a EE. UU. El trabajo de campo en el que se basa este artículo se ha desarrollado durante los años 2016 y 2017, en San Quintín, México, y en Oxnard, EE. UU., donde la presencia de las mismas corporaciones agroalimentarias permite un análisis de sus estrategias económicas y territoriales. La metodología se ha basado en técnicas cuantitativas $\mathrm{y}$, especialmente, cualitativas.

Palabras clave: 1. jornaleros migrantes, 2. corporaciones agroalimentarias, 3. cultivo de fresas, 4. Valle de San Quintín-Baja California, 5. Oxnard-California.

\section{ABSTRACT}

The article will analyze different recruiting methods adopted by local farms located in the San Quintin Valley, in Baja California, and transnational companies that operate in the strawberry sector in both Mexico and the United States. This valley is a fundamental route for migrants from southern Mexico who travel to the north of the country and the U.S. The article draws on the fieldwork carried out during 2016 and 2017, in San Quintin and Oxnard (U.S.), where the presence of the same agri-food corporations allows an analysis of their economic and territorial strategies. The methodology has been based on quantitative and especially qualitative techniques.

Keywords: 1. migrant day laborers, 2. agri-food corporations, 3. strawberry crops, 5. San Quintin Valley-Baja California, 5. Oxnard-California.

Fecha de recepción: 31 de mayo de 2018

Fecha de aceptación: 09 de mayo de 2019

Publicación en web: 30 de septiembre de 2020

\footnotetext{
${ }^{1}$ Universidad Nacional Autónoma de México, México, a.garrapa@sociales.unam.mx, https://orcid.org/0000-0002-6945-8066
}

Migraciones Internacionales es una revista digital anual editada por

El Colegio de la Frontera Norte. https://migracionesinternacionales.colef.mx 


\section{INTRODUCCIÓN}

El Valle de San Quintín se ubica en el estado fronterizo de Baja California, y constituye uno de los principales enclaves agrícolas de la región agroexportadora del noroeste mexicano, que incluye los estados de Sonora, Sinaloa, Baja California y Baja California Sur. Este territorio rural se especializa en la producción de hortalizas, sobre todo de tomate, y más recientemente, de fresas y otras bayas destinadas a la exportación para el cercano mercado estadunidense (Garrapa, 2019). Estos productos requieren una elevada intensidad de capital y mano de obra. Por lo que, a partir desde los años ochenta y noventa, paralelamente a la expansión de la explotación agrícola en el área, se han sucedido flujos de migrantes procedentes del sur y del centro del país, enganchados directamente en las comunidades de origen o llegados desde otros estados rurales, sobre todo de Sonora y Sinaloa. Los migrantes llegaban al Valle de San Quintín para trabajar como jornaleros asalariados y, en muchos casos, con el objetivo último de cruzar la frontera para buscar empleo en las ricas tierras norteamericanas (Velasco, Zlolniski y Coubès, 2014).

Este territorio representa entonces un observatorio estratégico para analizar las tendencias actuales de la circulación transnacional del capital y del trabajo, en el marco del sistema agroalimentario global. Por un lado, el Valle de San Quintín intercepta una de las trayectorias migratorias más tradicionales y masiva del mundo, la que cruza la frontera entre México y Estados Unidos; por otro lado, es un enclave agroexportador emblemático del proceder de las corporaciones agroalimentarias a nivel transnacional, a través de la expansión del modelo agrícola californiano. En el presente texto se analizará la relación existente entre los dos procesos, presentando la vinculación compleja que se desarrolla entre las estrategias de movilidad del capital corporativo y de los jornaleros migrantes, así como esta se manifiesta en el específico Valle de San Quintín y en el marco de una dinámica territorial mucho más amplia, que llega a conectar diferentes áreas de México, de Estados Unidos y otros continentes.

La investigación se ha desarrollado en dos áreas de producción fresera a través de varias etapas de trabajo de campo llevadas a cabo entre marzo de 2016 y julio de 2017 el Valle de San Quintín, en Baja California, México, y en Oxnard en California, EE. UU. Los dos territorios se caracterizan por la presencia de las mismas compañías norteamericanas y la migración de jornaleros originarios del sur y centro de México. La metodología de investigación se ha basado en una combinación de diferentes técnicas, cuantitativas y cualitativas, que incluyeron: la recopilación tanto de datos secundarios publicados por fuentes administrativas y estadísticas, como de la documentación producida por fundaciones privadas, institutos de investigación, asociaciones y sindicatos; la observación directa y la 
participación en las actividades de algunas asociaciones locales, ${ }^{2}$ la realización de entrevistas semiestructuradas (95 en total) con empresarios agrícolas, trabajadores, representantes de instituciones locales y de diferentes organizaciones sociales y sindicales.

Respecto al estudio de la movilidad transnacional en el marco de la globalización, algunos teóricos estructuralistas (Castles y Miller, 2004; Sassen, 1998) han evidenciado la contradicción existente entre la libre circulación del capital, las mercancías, las actividades productivas y las informaciones, por un lado, y el cierre de las fronteras frente a la movilidad de los trabajadores y en general, de las personas procedentes de algunos países más pobres, por otro. Según esta corriente de análisis, los territorios con bajo costo salarial exportan mano de obra y son destino de las estrategias de deslocalización de las empresas transnacionales; mientras los países del capitalismo avanzado recurren a la importación de trabajadores migrantes, menos tutelados y menos remunerados.

Al contrario, los enfoques transnacionales y de redes sociales, tomando en cuenta la creciente variedad de los flujos migratorios, han propuesto una serie de categorías analíticas que evidencian fundamentalmente una tendencia circulatoria y el repetido atravesamiento de fronteras físicas de los estados nacionales, así como de fronteras étnicas culturales y coloniales (Stephen, 2007; Tarrius, 2007). Varios autores (Levitt y Glick Schiller, 2004; Quesnel, 2010), enfocados a esta área de estudio, han indagado en el análisis de los espacios sociales transnacionales, definidos como campos sociales, campos migratorios y territorios circulatorios, archipiélagos y otros más, que ponen en relación las diferentes áreas de origen, de tránsito y de destino. Contrariamente al primer enfoque, estas contribuciones sustituyen o subordinan el estudio de las causas macroestructurales al micro y meso análisis de sujetos individuales, de los sistemas familiares y comunitarios. De hecho, Portes, Guarnizo y Landolt (2003) eligen priorizar la investigación de un transnacionalismo desde abajo, ${ }^{3}$ afirmando que las actividades transnacionales de origen popular no son impulsadas por acciones o políticas de gobierno, y tampoco por los administradores de las grandes corporaciones; por el contrario, estas actividades constituyen una reacción de los migrantes

${ }^{2}$ La investigación se desarrolló en colaboración con la organización Mixteco Indígena Community Organizing Project (MICOP), localizada en Oxnard, con el Sindicato Independiente Nacional Democrático de Jornaleros Agrícolas (SINDJA), y con las organizaciones sociales la Casa de La Mujer Indígena y la Alianza de Organizaciones nacional, estatal y municipal por la Justicia Social, que operan en el Valle de San Quintín, en Tijuana y en la Ciudad de México.

${ }^{3}$ Portes, Guarnizo y Landolt (2003) proponen una distinción conceptual entre globalización desde arriba y desde abajo: se refieren a las actividades llevadas a cabo, en el primer caso, por corporaciones multinacionales y Estados, en el segundo caso, por los migrantes y sus contrapartes familiares y comunitarias en el país de origen. 
y sus familias a la pobreza provocada por las políticas gubernamentales y las condiciones de capitalismo dependiente de los lugares de origen.

Sin embargo, a partir de la segunda mitad de los años 80, el escenario internacional se ha orientado hacia una exacerbación de las políticas migratorias, común a todos los países occidentales de vieja y de nueva inmigración, que han devenido siempre más estrictas a partir de los primeros años del 2000. En EE.UU. se ha agudizado este fenómeno, sobre todo después de la caída de las torres gemelas en el 2001. No obstante, en aparente contratendencia respecto a estas prácticas restrictivas, en varios países se ha mantenido la oportunidad de abrir las fronteras externas a la migración laboral temporal, según modalidades y grados diferentes de oficialidad o informalidad. Existe el caso de programas institucionales que prevén una colaboración entre organizaciones de los países de salida y de llegada (Sánchez Gómez y Lara Flores, 2015); también, de agencias privadas que se dedican al suministro de fuerza laboral temporal a nivel transnacional; intermediación informal por parte de redes sociales, manejadas por capataces y enganchadores y, a veces, encubiertas con apariencia de cooperativas de trabajo legales. Estas organizaciones intermediarias pueden ser ilegales o pueden estar reguladas oficialmente, hasta aparecer en los contractos colectivos de sector (Corrado, De Castro y Perrotta, 2016). Krissman (2005) destaca el papel de los empleadores que, recurriendo a varias formas de intermediación, influencian, junto a las políticas migratorias estatales, el funcionamiento y la estructuración de las redes de reclutamiento. De hecho, la organización de estas últimas se orienta con base en las solicitudes del mercado laboral receptor y de los intermediarios que promueven cadenas migratorias de acuerdo a las necesidades empresariales.

En el presente texto vamos a seguir estas últimas contribuciones explorando específicamente el caso de actividades transnacionales realizadas desde abajo por jornaleros migrantes y sus familias. Estos últimos reaccionan directamente frente al proceso de globalización desde arriba, llevado a cabo por corporaciones agroalimentarias y empresas agrícolas norteamericanas, que recurren a medidas establecidas por una política migratoria estatal de reclutamiento de trabajadores extranjeros temporales.

En el contexto de encadenamiento entre migraciones locales, regionales, nacionales e internacionales que se generan en áreas de agricultura intensiva, el Valle de San Quintín se caracteriza principalmente por dos especificidades. La primera, por ser territorio crucero, en el cual se enlazan movimientos de población local hacia otros rumbos y nuevos pobladores que llegan a sustituirlos desde otras áreas del país (Lara Flores, 2010); la segunda, por ser un territorio de reciente formación demográfica, con una muy joven identidad territorial de casi todos sus habitantes (Camargo, 2015). Lara Flores (2003) ha evidenciado la dimensión móvil y precaria de este enclave agrícola fronterizo, profundizando las condiciones de reclutamiento, de trabajo y residencia temporal de los jornaleros migrantes. Sucesivamente, otros autores (Velasco et al., 2014) han enriquecido el panorama de investigación dirigiendo su atención al proceso de sedentarización y de creciente arraigo de los nuevos colonos del 
Valle. En este artículo regresamos a estudiar la dimensión circular, nacional y transnacional, que involucra al Valle de San Quintín y particularmente, la movilidad que corresponde a las maniobras territoriales de las corporaciones transnacionales freseras.

Integrando los aportes teóricos enfocados a la circulación del capital y de los trabajadores, queremos evidenciar cómo se construyen las cadenas globales de mercancías y de valor (Gereffi, Humphrey y Sturgeon, 2005), las redes globales de producción (Dickens, 1998), o los territorios-archipiélago corporativos (Ceceña, 2017), a partir de las múltiples localizaciones de sus actividades extractivas, tanto de recursos naturales como de la fuerza laboral. En particular, analizaremos cómo a esos sistemas territoriales corporativos corresponden otros tantos archipiélagos (Quesnel, 2010) o sistemas y subsistemas (Durand, 2016) de migración laboral, acoplados a las necesidades del capital, así como a las estrategias económica familiares o comunitarias (Prunier, 2017).

El texto empezará perfilando la estructura productiva local y el papel de las grandes comercializadoras norteamericanas en el contexto más amplio de la competencia económica entre territorios freseros. Seguirá el análisis de la estrategia de reclutamiento de la mano de obra por parte de las agencias intermediarias y de las grandes empresas activas en el territorio, locales y transnacionales. Se explorarán los flujos migratorios correspondientes a los archipiélagos productivos profundizando, por un lado, en la lógica económica que subyace a las estrategias corporativas de movilización de la mano de obra; por otro lado, sus consecuencias sociales y la forma en la que los trabajadores responden a las fuerzas económicas nacionales y globales, para canalizar sus propios objetivos familiares, intereses comunitarios y lucha de clase.

\section{GLOBALIZACIÓN DESDE ARRIBA: ESTRATEGIAS CORPORATIVAS Y COMPETENCIA INTERTERRITORIAL}

Baja California es uno de los estados productores de fresa más importantes de México, ubicándose en segundo lugar después de Michoacán. En el año 2016 (OEIDRUS, 2016b), la superficie estatal cultivada representó 25 por ciento de la superficie total del país con 2531 hectáreas (ha) cosechadas, y aportó 32 por ciento del valor total de producción del país con 82608 toneladas (ton). En el momento del análisis, el Valle de San Quintín incluía las delegaciones de Punta Colonet, Camalú, Vicente Guerrero y San Quintín. ${ }^{4}$ En particular, se cultivaron 1119 ha de fresas en la delegación Vicente Guerrero, y en otras localidades como 730 ha en San Quintín, 631 ha en Camalú y 50 ha en Colonet (OEIDRUS, 2016a; SAGARPA 2015). En segundo lugar, está la producción de frambuesas, con 9152 ton producidas desde 511 ha; sigue la producción de arándanos con 1875 ton desde 140 ha y en última posición está la producción de zarzamoras, con 536 ton de cosecha en 51 ha. En total se produjeron

\footnotetext{
${ }^{4}$ Estas delegaciones son parte de las ocho delegaciones del municipio de San Quintín, creado en febrero de 2020.
} 
más de 94171 ton de bayas en aproximadamente 3233 ha, la mayoría cultivadas a cielo abierto en la zona costera del estado. Aproximadamente 90 por ciento de esta producción se destinó a los mercados internacionales, principalmente de Estados Unidos, mientras que el restante 10 por ciento se destinó al mercado regional y nacional.

La estructura productiva del sector fresero en el Valle de San Quintín se caracteriza básicamente por la presencia de muchos pequeños agricultores y grandes empresas agrícolas mexicanas, extranjeras y mixtas (trabajo de campo). Las corporaciones transnacionales activas en el sector son productoras y comercializadoras de origen estadounidense: Driscoll's y Andrew and Williamson Fresh Produce $(A \& W)$, y destacan por ser las más relevantes entre todas las que operan en el Valle. Estas últimas, además de cultivar directamente en tierra propia y rentada, adquieren cantidades adicionales de producto, contratando pequeños y grandes agricultores locales, según acuerdos económicos y formas jurídicas diferentes. La creciente intervención de estas compañías transnacionales influye en la estructura productiva y en la organización del trabajo agrícola, alimentando un proceso de concentración económica a nivel local, impulsado por las características propias del cultivo de fresas.

De hecho, el empobrecimiento del suelo y la sobreexplotación de los recursos acuíferos, junto a la expansión del cultivo de las fresas, que son muy sensibles a la salinidad del agua y a la composición arenosa del suelo, han contribuido a la expulsión de muchos pequeños productores que no tienen capital de inversión suficiente para buscar agua en profundidad o para comprar máquinas desaladoras. A esto se suman las estrategias de expansión territorial que las transnacionales de fresas han desarrollado para acaparar la producción invernal del Valle, estipulando acuerdos con los agricultores locales y creando empresas productoras mexicanas surgidas desde las mismas comercializadoras.

La empresa Driscoll's, por ejemplo, es la comercializadora norteamericana más grande y conocida en el Valle de San Quintín, líder mundial del mercado fresco de las bayas. Fundada como una pequeña empresa familiar a finales de 1800 , ha crecido exponencialmente y actualmente es una sociedad transnacional que maneja la fruta producida en diferentes territorios de Estados Unidos, México, Europa y África (Driscoll's, 2018), y exporta hacia varios países del mundo a través de las más grandes cadenas de supermercados, como WalMart, Costco y Tesco.

Esta corporación transnacional ha logrado ventajas competitivas muy fuertes, fundamentalmente desarrollando biotecnología propietaria y persiguiendo múltiples estrategias de expansión territorial. Mientras que otras compañías utilizan prevalentemente variedades de plantas seleccionadas por la Universidad de California y de Florida, Driscoll's Berry ha invertido privadamente en un departamento de investigación genética. Este departamento, propio de la empresa, desarrolla variedades que son más resistentes a las enfermedades y adaptables a los cambios climáticos, con características estéticas y 
organolépticas preferidas por el mercado, que alcanzan temporadas extraordinariamente largas de cosecha, con mayores rendimientos y consecuentemente mayores ganancias. Además, la compañía gestiona ingentes flujos de producción a través de una serie de acuerdos y contratos con una amplia base de productores, independientes o reunidos en sociedad, y gracias a empresas agrícolas que realizan cultivo exclusivamente a esta compañía, pero manteniendo un estatus jurídico autónomo, como en el caso de las asociadas a la Reiter Affiliated Companies (RAC).

De hecho, después de la Segunda Guerra Mundial las empresas familiares Reiter y Driscoll, cultivadoras de fresas en California ya desde el inicio del siglo XX, comenzaron a comercializar fresas bajo la etiqueta de Driscoll Strawberry Associates, junto a otra familia y proveedores asociados. La compañía Reiter es fundadora y todavía empresa principal de la sociedad productora $R A C$, que produce para su único cliente, la comercializadora Driscoll's. La familia Reiter ocupa la presidencia de Driscoll's y sigue manejando ambas sociedades (Bloomberg, 2018), así que, efectivamente, Driscoll's y $R A C$ son parte del mismo capital californiano, actualmente manejado por la familia Reiter, simplemente repartido entre compañía especializada en comercialización y su proveedora productiva. Actualmente la producción de las empresas afiliadas a Reiter está distribuida entre varios territorios norteamericanos de California (Oxnard, Santa María, Watsonville y Salinas), Oregón y Florida; pero también se ha ido expandiendo a nivel internacional, posicionando estratégicamente cada empresa para ajustarse a la demanda continua de bayas. Desde el año 1991 RAC opera en Baja California y el centro de México a través de BerryMex; con Maravilha Farms está en Portugal desde el 2006; gracias a las relaciones comerciales de Driscoll's con productores en el sur de España, ha llegado en 2011 hasta Marruecos, para cultivar con Atlas Berry Farms (RAC, 2018).

También está la compañía norteamericana $A \& W$, que no es líder del sector como Drsicoll's, y que además de las fresas comercializa tomates. A pesar de ser una empresa originada como negocio familiar, que durante las últimas tres décadas ha logrado devenir en una sociedad productora y comercializadora de alcance transnacional, todavía tiene una capacidad económica inferior a la de Driscoll's, y una expansión territorial de carácter exclusivamente regional (México y EE. UU.). Las familias Andrew y Williamson, que fundaron la compañía en 1986, comenzaron cultivando tomates y fresas de invierno en Baja California (Andrew \& Williamson, 2018). Durante toda la primera década del 2000, la empresa se expandió en varias zonas rurales de México (hacia el oeste, al centro y Baja California Sur) y en el año 2005 se fusionó con Sundance Berry Farms, empresa líder en la producción de fresas en California, alcanzando así comercializar la fruta durante todo el año.

En general, las estaciones de producción de fresa se suceden en los varios distritos rurales de Baja California y California, configurando cierta circularidad anual, pero también se superponen durante algunos meses, en los cuales se acumula la oferta de fruta en el mercado final, descendiendo el precio de los productos. La temporada de cosecha empieza 
simultáneamente en la zona de Oxnard y de San Quintín, centrándose durante los meses de invierno y primavera en ambos territorios, con un pico productivo que por lo general va de marzo hasta mayo. Luego continúa en otros territorios de California, primero en Santa María, que empieza a producir alrededor de marzo y continúa haciéndolo durante el verano, siendo desplazada sucesivamente por el área de Watsonville, que llega hasta finales de otoño, y de ahí vuelve a empezar el ciclo. La estacionalidad productiva del centro de México, que coincide aproximadamente con la de Oxnard y de San Quintín, empezando un poco después y terminando un poco antes y no compite realmente con los enclaves californianos, ya que su producción se dirige al mercado de exportación de la costa este de Estados Unidos, donde se confronta con la misma temporada de Florida.

La competencia entre diferentes territorios rurales se juega no solo con base en la superposición temporal de las cosechas, sino también dependiendo de la presencia o ausencia de varios factores que pueden ofrecer ventajas competitivas a las corporaciones transnacionales: la disponibilidad y el bajo costo de la mano de obra, las condiciones climáticas y el bajo costo de explotación de los recursos naturales accesibles, como la tierra y el agua, la flexibilidad de las normas ambientales y la cercanía con el mercado final. Presentamos como ejemplo el análisis comparativo de las características sociales, económicas y ecológicas entre Oxnard y San Quintín hecho por un productor y representante de BerryMex.

Estados Unidos tienen muchísima presión, en todos los sentidos: económicas, ecológicas. En Oxnard, por ejemplo, la ciudad se está comiendo la agricultura y se va reduciendo mucho la tierra para cultivo, tienen muchas restricciones para el tema de agroquímicos, la tierra y el agua son cinco veces más caras que aquí [San Quintín]. El coste de la mano de obra también es al menos ocho veces más caro [de México] y el sueldo mínimo en California va a subir y eso los echa afuera del mercado. Entonces estamos mirando a México como el sustituto de la producción en California. Los márgenes de utilidad que están logrando [los productores] en Estados Unidos son muy reducidos y nosotros aquí tenemos mucho más margen (Productor y representante de BerryMex, comunicación personal, 15 de abril de 2017, Valle de San Quintín).

Como evidencia este testimonio y otros recopilados en ambos territorios, la zona fresera de Oxnard está siendo progresivamente desplazada y potencialmente será sustituida por el Valle de San Quintín, en el marco de la lógica territorial corporativa. A pesar de ser más cara que otras, su producción permanecerá en el programa anual de suministro de las compañías transnacionales; en este caso Driscoll's, hasta que el área permita cumplir con la estrategia de mitigación del riesgo general, para cubrir una posible falta en la producción de otros territorios con estaciones similares, debida a eventos climáticos o fitológicos imprevistos y destructivos. El problema subsiste para los productores que radican solamente en un territorio, y que en tales casos pueden fracasar o ser expulsados del mercado. Por lo tanto, la supervivencia económica de los agricultores locales depende cada vez más de su pertenencia 
a las grandes redes de las corporaciones comerciales, a menos que no dispongan de capital suficiente para desarrollar las mismas estrategias de expansión territorial, bastante amplias, diversificadas y preferiblemente de alcance transnacional.

Entre los varios aspectos que constituyen los factores de ventaja o desventaja a nivel territorial, destacamos la importancia de la disponibilidad de la mano de obra barata y el posible manejo de sus características sociales, económicas y políticas, según la estrategia empresarial. De hecho, en el ámbito laboral hay una diferencia notable entre las prácticas operadas por las grandes empresas locales y las dos transnacionales activas en el Valle de San Quintín.

Driscoll's y $A \& W$ comercializan fruta para el mercado fresco de exportación, el cual proporciona las mayores ganancias del sector. Por esta razón, las dos corporaciones compran y cosechan a través de sus empresas productoras dotadas de personalidad jurídica mexicana, hasta que reciben demandas del mercado fresco norteamericano y que las variedades cultivadas les permiten lograr una buena calidad. Una vez que se acaba la cosecha de fruta fresca destinada a las cadenas estadounidenses minoristas, las corporaciones comercializan la fruta de otros territorios que siguen produciendo en el ciclo estacional corporativo.

Al contrario, los grandes agricultores locales, independientes o proveedores de $A \& W^{5}$, siguen vendiendo por un precio menor la fruta fresca de segunda calidad al mercado nacional, o la cosechan para el mercado estadounidense de fruta congelada y procesada. Lo hacen para alcanzar los cultivos de verano, de tomate o de pepino, teniendo un mínimo de ingreso y manteniendo empleados a los jornaleros de sus plantas base. También recurren a estas salidas secundarias del mercado durante los periodos de mayor escasez de fuerza laboral. De hecho, según los actores entrevistados en el Valle, la falta de mano de obra ha ido creciendo durante los últimos años y los empleadores lamentan sobre todo la emigración a Estados Unidos de trabajadores con experiencia, particularmente durante la temporada de primavera y verano, como nos comenta el dueño de una grande empresa agrícola local.

No es que me falte tanta gente, es que me falta calidad de gente. Porque se están llevando mucha gente calificada de México, con el H-2A. Entonces me llevan gente que me hace 80 cajas diarias y me llega gente que me hace 20 cajas. Porque me llega gente nueva, del sur, que hay que capacitar. O se quedan las señoras, los abuelitos, que hacen 15 cajas diarias y entonces mi rendimiento en cosecha disminuye. Cada año tengo que traer nuevos trabajadores, una parte. También tengo gente que tiene con nosotros un buen tiempo, pero cada vez se están yendo más de los mejores para Estados Unidos. Y esos que llegan, cuando alcanzan un cierto nivel de experiencia

\footnotetext{
${ }^{5}$ En el modelo contractual desarrollado por Driscoll's, el agricultor recibe exclusivamente variedades propietarias, que está obligado a destruir una vez que cumpla con la cantidad de producción requerida por la misma comercializadora.
} 
y rapidez, también aplican para allá (Gran productor local, comunicación personal, 20 de marzo de 2017, Valle de San Quintín).

Es interesante destacar el papel de territorio-puente del Valle de San Quintín, que como analizaremos en seguida, es utilizado por ambos actores, trabajadores y empleadores, como área rural fronteriza de entrenamiento, específicamente en la cosecha de bayas, finalizado al reclutamiento temporal en los campos de Estados Unidos. En síntesis, y en contraste con lo afirmado por Portes, Guarnizo y Landolt (2003), existen cuatro tipos principales de actores empresariales e intermediarios laborales que participan al impulsar la circulación estacional de los jornaleros, hacia y desde el Valle: los grandes agricultores locales, las corporaciones transnacionales, varios tipos de contratistas informales y agencias de suministro de trabajo temporal. Los movimientos migratorios se articulan en dos grandes flujos principales: los jornaleros, que llegan desde el sur y el centro de México y que son movilizados para compensar la falta de mano de obra durante los picos productivos en el Valle de San Quintín, y los colonos del Valle, reclutados para ir a trabajar estacionalmente con la visa temporal H2A en diferentes áreas californianas.

\section{La circulación laboral}

Con respecto al primer tipo de flujo migratorio, son los grandes agricultores del Valle quienes contribuyen principalmente a la movilidad de jornaleros procedentes de otros territorios nacionales. Estos últimos son reclutados por enganchadores, que traen mano de obra sobre todo desde comunidades rurales e indígenas del centro y sur de México, prometiendo empleo bien pagado y alojamiento gratuito en los campamentos empresariales para trabajadores temporales. Una vez que llegan los camiones al Valle de San Quintín, los agricultores pagan a los transportistas según el número de jornaleros que efectivamente se quedan a trabajar en sus campos por lo menos un número mínimo de días, como explica la encargada de atención social a los trabajadores de una grande empresa local.

Ahorita hay muchos contratistas, gente que viene desde Oaxaca, Veracruz, Sonora. Marcan, buscan las empresas y te dicen 'tengo 40' o 'llevo dos camiones'. Y cobran el costo del camión, como 40000 pesos se paga el camión, más la comisión para la gente. Pero el año antepasado se contrataron tres camiones y cuando pasaban allá por Ensenada se bajaba la gente y ya no más llegaba medio camión. O a veces nomás llegan a la localidad y se van. Cruzan, usan este lugar como puente. Entonces a veces le dice la empresa al contratista 'a ver, que trabajen tres días, para saber que sí se va a quedar la gente a trabajar y ya te pago' (Encargada empresarial, comunicación personal, 7 de julio de 2017, Valle de San Quintín).

Todavía hay flujos de migrantes que se dirigen a Estados Unidos desde el Valle, así como desde otros territorios fronterizos, intentando cruzar la frontera sin papeles; no obstante, a partir de los años 2000, la frontera norte de México se ha hecho mucho más cerrada y 
peligrosa. La actual política antimigratoria estadounidense está interrumpiendo la tendencia circulatoria (Levitt y Glick Schiller, 2004; Tarrius, 2007 de los jornaleros mexicanos indocumentados que cruzaban la frontera para ir a visitar los familiares en sus tierras de origen y luego regresar a trabajar en los Estados Unidos. La drástica reducción de las oportunidades de atravesamiento de la frontera física contribuye a la progresiva ruptura de los vínculos y de múltiples intercambios entre las diferentes áreas de origen, de tránsito y de destino que conforman los archipiélagos de los migrantes todavía indocumentados. Con la agudización de los controles fronterizos, el precio del pasaje irregular por las montañas de Tijuana es cada vez más elevado, así como el riesgo de ser asaltados por bandas armadas o aprendidos por agentes de migración. Por lo tanto, los jornaleros que actualmente salen del Valle para trabajar en Estados Unidos intentan aprovechar la visa temporal H-2A, o sea, la versión más reciente del antiguo programa Braceros, pero manejada de manera privada por los empleadores estadounidenses.

En contraste con el Programa Bracero, que derivó de un acuerdo entre los gobiernos de Estados Unidos y México, en el caso de las visas $\mathrm{H}-2$ se trata de una iniciativa unilateralmente adoptada por el gobierno estadounidense, que ha asignado la gestión del procedimiento a los empresarios agrarios, que a su vez recurren a organizaciones intermediarias y enganchadores de vario tipo (Trigueros Lagarreta, 2015). El programa H2A de trabajadores agrícolas temporales fue instituido en 1986 con la Immigration Reform and Control Act (IRCA), para enfrentar la escasez de mano de obra en la agricultura estadounidense (Trigueros Lagarreta, 2015; Palerm, 2014).

El IRCA permitió la legalización de alrededor de tres millones de extranjeros indocumentados, entre quienes residieron en EE. UU. de manera continua y fuera de la ley desde 1982, y los que hubieran laborado en la agricultura estadounidense al menos 90 días en el año anterior (1985) bajo el programa llamado Special Agriculture Workers (SAW). Dividió la visa temporal H-2 (1952) para la importación de mano de obra no calificada, en H-2A para trabajadores agrícolas y H-2B para los no agrícolas (Trigueros Lagarreta, 2015). De hecho, con el pasar del tiempo, se ha institucionalizado el programa de trabajadores temporales, como medio de reclutamiento constante de mano de obra complementaria a la local, pero sin otorgar a cambio la opción de conseguir la residencia definitiva (Izcara Palacios, 2015). El movimiento de los jornaleros asentados en el Valle de San Quintín y reclutados con la visa temporal $\mathrm{H}-2 \mathrm{~A}$ constituye el segundo tipo de flujo migratorio analizado en la presente investigación. De todos modos, es necesario destacar que, a pesar de la falta de datos cuantitativos actualizados, los jornaleros migrantes indocumentados representan todavía una componente fundamental del total de los trabajadores empleados en el sector agrícola estadounidense y particularmente californiano (Palerm, 2014).

Actualmente, al crecimiento del flujo de jornaleros temporalmente documentados desde el Valle de San Quintín hacia los territorios estadounidenses contribuye a la conformación de tres tipos diferentes de intermediarios laborales oficiales. Un primer tipo es representado 
por Fresh Harvest, una empresa de servicios que suministra mano de obra temporal a diferentes empleadores norteamericanos, para las cosechas de bayas y verduras en Arizona y sobre todo en California (Fresh Harvest, 2018). El segundo caso es el de Sierra-Cascade Nursery, una empresa norteamericana especializada en la producción y selección de plantas, que recluta jornaleros en el Valle para emplearlos temporalmente en sus viveros de Susanville o Tulelake, entre los muchos localizados en Oregón, Nevada y sobre todo California (Sierra-Cascade Nursery, 2018). Finalmente, están las compañías transnacionales $A \& W$ y Driscoll's, que manejan varios flujos de jornaleros, según los picos productivos de las áreas involucradas en su red corporativa. Driscoll's moviliza trabajadores a través de la agencia de reclutamiento de BerryMex.

Todos estos intermediarios laborales actúan formalmente para movilizar jornaleros desde el Valle por medio de la visa H-2A. Seleccionan y reclutan la mano de obra considerada idónea, facilitando los trabajadores, a través de una red de encargados, en el cumplimiento del proceso burocrático para la obtención de la visa en el consulado de Tijuana, desde donde los llevarán directamente a los campamentos de las empresas empleadoras. El trabajador anticipa los costos de todo el procedimiento, que será rembolsado, junto a los costos de transporte hasta la frontera, una vez que haya completado buena parte del contrato de trabajo, hasta 50 por ciento en el caso de Sierra-Cascade Nursery. Si la visa no es otorgada al jornalero, todo el gasto queda a su cargo.

Es interesante analizar los principales aspectos de este contrato binacional, entre los muchos detalles económicos y legales que lo caracterizan. Primero, surge el papel de territorio-puente que juega el Valle de San Quintín, interpretado por las mismas reclutadoras como área rural de entrenamiento y especialización de los jornaleros, dirigidos sucesivamente a los campos norteamericanos. De hecho, a los trabajadores interesados se les piden ciertas características específicas: edad entre 18 y 38 años; certificación de buen estado de salud; presentación de una carta de trabajo o recomendación, firmada o sellada por un empleador; talones o recibos de pago, para comprobar de tener una sólida experiencia en empresas locales reconocidas. En el sitio internet de las reclutadoras está claramente anunciado:

Para trabajar durante nuestra temporada de cosecha, debe tener por lo menos tres meses de experiencia trabajando con cultivos de fresa dentro de los últimos dos años. Ocupará comprobar que tiene esta experiencia por medio de una carta de trabajo o talones de pago. [...] Desafortunadamente, no podemos contratar solicitantes que no tienen la experiencia requerida. Si Usted es muy motivado, sugerimos que busque trabajo localmente en la fresa para que pueda adquirir la experiencia requerida a calificar en el futuro (Sierra-Cascade Nursery, 2017).

En este sentido, Fresh Harvest ha desarrollado un dispositivo de prueba practica para comprobar la experiencia real, la especialización y la productividad del trabajador, el cual 
tiene que simular las operaciones de cosecha utilizando prototipos de frutas de plástico y herramientas puestas a disposición para el ejercicio en los locales de la agencia.

Durante años recientes, se ha agudizado la tensión entre agencias intermediarias y empresas agrícolas porque, por un lado, las primeras han llegado a lamentar la falta de veracidad de los comprobantes presentados por algunos trabajadores, que una vez llegados en Estados Unidos no tenían la productividad esperada; por otro lado, los patrones locales y las transnacionales han negado comprobantes a los jornaleros que aplican para irse, por su molestia debido a la escasez de mano de obra provocada por la intensa actividad de reclutamiento de las agencias.

Naturalmente, las reclutadoras de las corporaciones transnacionales no necesitan pedir este tipo de comprobantes de verificación, ya que manejando su propia mano de obra, tienen muy bien controlados todos los datos personales, la productividad, la conducta y hasta la orientación política de los jornaleros seleccionados para trabajar temporalmente en otros ranchos californianos de la misma corporación, como nos explica el encargado local de las operaciones de reclutamiento de BerryMex.

Seleccionamos a la gente que haya trabajado la temporada, que tiene una muy buena conducta, que no tenga ninguna queja, o sea quienes hayan respetado todas las reglas...pues un buen trabajador para la empresa. Primero se les da la preferencia a los que están en los cultivos de fresa, después a los de la mora y los arándanos [...] Vamos, hablamos con la gente y los que quieren ser partícipes llegan a las oficinas a entregar la documentación. Primer filtro es que tengan el pasaporte y toda la documentación vigente. Segundo filtro, revisamos que no tengan ningún antecedente en el campo, que no haiga ninguna nota que su mayordomo haya apuntado. La tercera, mandamos la carta de antecedentes penales y el certificado médico. En términos de productividad nos guiamos en eso: que sea un buen promedio de 4 o 5 cajas por hora (Encargado de BerryMex, comunicación personal, 2 de julio de 2017, Valle de San Quintín).

Según varios productores y funcionarios responsables del sector agrícola entrevistados en Oxnard y Ventura, California, la visa H-2A es insuficientemente para responder a la demanda de trabajadores estacionales. En particular, los testimonios ponen de relieve algunas dificultades encontradas en el uso del programa: por un lado, lamentan elevados gastos de viaje y de sustento de los trabajadores, sobre todo de la vivienda; por otro lado, la complejidad y la lentitud del procedimiento burocrático no encaja bien con la rapidez y fluidez de las operaciones agrícolas. El número de trabajadores indocumentados ya presentes en el territorio californiano, es amplia mayoría entre los jornaleros empleados por las empresas agrícolas. Sin embargo, el endurecimiento de las medidas de control fronterizo y la verificación de la autenticidad de los documentos han obligado a los empresarios a recurrir cada vez más a este medio legal de reclutamiento de la fuerza laboral migrante (Trigueros Lagarreta, 2015). Este fenómeno ha sido particularmente evidente en el estado de California, 
que tradicionalmente demandaba muy pocos trabajadores $\mathrm{H}-2 \mathrm{~A}$, contando con una gran oferta de trabajadores indocumentados y que todavía están ampliamente presentes en el territorio: en 1999 se registraron solo 514 trámites de visas certificadas, lo cual representaba 1.2 por ciento del total federal, en 2013 los trámites de visas llegaron a ser 2815 (U.S. Department of Labor, citado en Trigueros Lagarreta, 2015).

En el caso específico de las compañías transnacionales, la coordinación entre los territorios de la red corporativa permite manejar con cierta eficacia la temporalidad circulatoria de los jornaleros, incluso, de los que son movilizados con la visa $\mathrm{H}-2 \mathrm{~A}$. Seleccionar a los jornaleros con criterios de productividad permite a las empresas agrícolas estadounidenses obtener niveles crecientes de rendimiento del dinero invertido en la contratación y mantenimiento de la mano de obra extranjera. Además, la selección de los trabajadores con base en sus características y comportamiento se ve reforzada por la frecuente separación espacial de su alojamiento con respecto a la población local, y por las reglas de funcionamiento del mismo programa de visa temporal, ya que el permiso de residencia es otorgado exclusivamente vinculado a la empresa empleadora. Esta última condición contractual garantiza un fuerte control no solo del ingreso del jornalero al país, y de su salida en cuanto acabe el trabajo, sino también de sus prestaciones laborales y de su comportamiento durante toda su estancia laboral. Si el trabajador decide por alguna razón interrumpir anticipadamente el contrato, o si no responde a las expectativas de productividad y buena conducta, tendrá que irse inmediatamente del país y cubrir sus gastos de regreso, tendrá un registro negativo y no podrá acceder a esta oportunidad en los años siguientes. El jornalero migrante se encuentra entonces constantemente amenazado por la posibilidad de ser expulsado, si la empresa decide despedirlo o él no quiere continuar la relación laboral.

Además, hay que destacar que los jornaleros, a pesar de ser dotados de un número de seguro social y de poder recibir atención sanitaria en caso de accidente o enfermedad, de hecho, no tienen acceso a prestaciones sociales ni garantías laborales en Estados Unidos, como las que podría corresponder a la mano de obra local. Como nos informa sintéticamente Trigueros Lagarreta (2015), los trabajadores que poseen la visa H-2A, además de estar atados al empleador aun cuando éste no cumpla con las condiciones contractuales, no están amparados por el Migrant and Seasonal Agricultural Worker Protection Act, que regula los estándares y condiciones laborales en la agricultura. Tampoco están protegidos por la Federal Unemployment Tax Act, que establece los beneficios del desempleo, ni por la National Labor Relations Act, que otorga derecho a la negociación colectiva. Además, por la misma naturaleza unilateral del programa estadounidense, los jornaleros mexicanos tampoco están cubiertos por la Ley Federal del Trabajo de su país y el gobierno mexicano interviene únicamente en caso de violaciones a los derechos humanos y laborales a través de la limitada acción de algunos cónsules mexicanos. Generalmente, los migrantes temporales no conocen sus derechos y no saben a quién recurrir en caso de problemas, ni con respecto al proceso de reclutamiento llevado a cabo por las organizaciones intermediarias, ni durante 
su estancia laboral en Estados Unidos, ya que se les mantiene bien lejos del alcance de las organizaciones sociales y sindicales activas en territorio norteamericano. De todas formas, los trabajadores prefieren mantener buenas relaciones con los empleadores para que los sigan contratando en los años siguientes, lo cual les permitiría ahorrar para contribuir a la economía familiar y a la mejora de las condiciones de vida en el territorio originario o en un nuevo asentamiento.

Finalmente, es interesante evidenciar cómo el filtro político y actitudinal descrito para el caso del visado H-2A, se aplica también a los trabajadores reclutados desde el sur y centro de México para ser empleados en los campos del Valle, y cómo estos criterios de selección se extienden a toda la comunidad de origen. De hecho, las empresas y los enganchadores adoptan estrategias de sustitución y reclutan jornaleros temporales de diferente procedencia como respuesta a eventuales movimientos reivindicativos, ya que identifican negativamente la caracterización cultural y geográfica específica de los líderes comunitarios y de los trabajadores considerados como más revoltosos. Cerramos este apartado con el testimonio del mismo encargado del reclutamiento de BerryMex, quien maneja una parte del conjunto de flujos migratorios que utiliza la empresa internamente en los territorios de su red productiva transnacional. Con el soporte de dispositivos legales como el visado $\mathrm{H}-2 \mathrm{~A}$, preparados por políticas migratorias de gobierno, la compañía dirige desde arriba la circulación temporal y espacial de sus empleados, con el fin de gestionar la disponibilidad de mano de obra según los diferentes picos productivos del archipiélago corporativo.

Reiter en Estados Unidos lleva gente de Guadalajara, Michoacán y Baja California. [...] Los que se van antes a Estados Unidos son los de Michoacán, en marzo o abril. Desde la misma BerryMex hacia Reiter. Cuando estamos atrasados un poquito aquí, de allá nos los prestan y se vienen aquí a la fresa y nos apoyan dos o tres semanas. De aquí, ya cuando los ocupan allá en Estados Unidos, ellos se van. El grueso va de Michoacán a Estados Unidos, y luego activan nuestra reserva y de aquí van a Watsonville o donde los necesitan. Porque en marzo, abril, mayo, también nosotros estamos en nuestra temporada y es cuando necesitamos y empezamos a batallar con la gente y aquí hay una competencia impresionante para acaparar a los trabajadores. A mediados de mayo ya no nos preocupa tanto y entonces ya empezamos a sacar el listado de la gente que se quiere ir para Estados Unidos (Encargado local de BerryMex, comunicación personal, 2 de julio de 2017, Valle San Quintín).

Seguimos ahora explorando el punto de vista de los trabajadores, ya no solo en calidad de factores productivos, sino también tomando en cuenta la forma en que estos responden a las fuerzas económicas nacionales y globales que impulsan el proceso de globalización desde arriba descrito hasta aquí. Particularmente, se analizan dos tendencias que surgen desde el mismo contexto de pobreza y explotación, pero que determinan dos dinámicas diferentes de globalización desde abajo: por un lado, las motivaciones personales que subyacen a los movimientos migratorios hacia los campos de Estados Unidos, con los retos y las 
consecuencias socioeconómicas que esta circulación implica para el núcleo familiar; por otro lado, la tensión organizativa del movimiento reivindicativo de los jornaleros asentados hacia una dimensión nacional y transnacional.

\section{Globalización desde abajo: motivaciones, desafíos y organización de los jornaleros}

Las difíciles condiciones de vida y de trabajo que originaron el levantamiento de los jornaleros y jornaleras en el Valle de San Quintín durante el marzo de 2015 (Jaloma, 2016; Aragón, 2015), están vigentes todavía en buena parte del Valle. El promedio anual salarial no resuelve el nivel de pobreza de los trabajadores, a lo que se añade la falta de acceso real de prestaciones sociales, entre ellas, la atención sanitaria. Todo ello forma parte de las razones principales de descontento y de emigración de muchos jornaleros asentados en el Valle.

Efectivamente, la calidad de vida de una familia de jornaleros es todavía muy mala, a pesar del notable esfuerzo físico cotidiano que hacen para mejorar sus condiciones de vida. Por un lado, los costos de vida son medianamente altos debido a la falta de servicios básicos, lo que obliga a los jornaleros a contratarlos como servicios privados: es el caso del agua potable en varias colonias del Valle. Por otro lado, el promedio salarial diario registrado en el año 2017 durante el trabajo de campo, era de entre de 160 y180 pesos mexicanos, excluyendo las pocas semanas de cosecha de fresas pagadas a destajo, que son las que usualmente les permiten obtener ganancias mayores durante un breve periodo del año, según el rendimiento físico individual. Por lo tanto, los jornaleros que logran disponer de la información, la documentación y las condiciones requeridas por alguna de las agencias intermediarias o corporaciones transnacionales presentes en el territorio, se van para Estados Unidos a trabajar por temporadas que puede llegar a cubrir muchos meses del año. Presentamos un fragmento de la entrevista a una jornalera de origen mixteco, que llegó al Valle cuando tenía 13 años y que nos permite entender más extensamente las razones de la circulación temporal a las que se integran los colonos, que son jornaleros ya asentados.

Es que aquí con lo que uno gana no alcanza el dinero y allá sí te rinde un poco más. Ponle unos 100 dólares al día, allá ganas tus 700, 800 dólares la semana y i¿cuánto ganas a la semana aquí?! La fresa dura seis meses, pero lo bueno es como un mes, donde uno gana más. Una semana o dos semanas que ganas 3 500, 4000 pesos... jel que sabe! Porque va según de las cajas que logras hacer. Después vas sacando 1800 , ponle 2000 pesos a la semana y ya de mes en mes va bajando y te vas a trabajar en el tomate u otra cosa. Entonces cuando uno gana más es cuando aprovecha para comprar zapatos y pantalones para vestirte, cosas para la escuela y ropa de cambio para los hijos. Porque después viene el pago por día y te dan tus 180, 200 pesos. Por eso aquí la gente no puede construir su casa, porque gana por puro comer en los meses que no hay fresa. [...] Este terrenito lo compramos que solo tenía una casita chiquita de madera y mi marido lo hizo todo porque se iba a trabajar en 
Estados Unidos, si no aquí no tuviéramos nada. Él empezó a ir y fueron cinco años de ir y volver. Se quedaba allá ocho o nueve meses, diez meses a veces, casi todo el año. Así fue hasta que ya los niños no quisieron que se fuera. Ahora tenemos que trabajar los dos para puro vivir. Allá atrás tengo la letrina, pero aquí en la casa falta hacer el baño, le falta piso, luz, taza, todo falta (Jornalera, comunicación personal, 20 de abril de 2017, Valle de San Quintín).

Como emerge de este testimonio y de otros recopilados, el objetivo principal de la emigración es apoyar la economía familiar, no sólo para su mantenimiento cotidiano, sino también para la construcción de una mejor vivienda, el desarrollo de oportunidades de empleo no agrícola y sobre todo para ofrecer una buena educación a los hijos. Lo confirma también otro jornalero también de origen oaxaqueño, criado en el Valle, y que nos comparte su experiencia directa como emigrado hacia los campos norteamericanos.

Yo digo, pues uno hace la lucha para tener algo aquí ¿no? Con lo que trabajas allá rinde acá, pero si te quedas allá no rinde. Lo bueno de eso es mandar todo para acá, porque si te quedas allá, así como lo ganas, así te lo gastas. [...] Yo estuve allá, fuimos con mi hermano y empezamos a ahorrar para construir y ya él empezó a abrir una tienda y yo abrí el Internet de poco a poquito, porque yo miré que es muy difícil tener toda la vida en el campo y hay personas ya mayores trabajando en el campo y es muy duro (Jornalero, comunicación personal 30 marzo de 2017, Valle de San Quintín).

Los fragmentos de la jornalera y el jornalero presentados, nos muestran una estrategia transnacional desarrollada desde abajo, negociada y establecida a nivel de núcleo familiar, que prevé la ausencia temporal, más o menos prolongada, de uno de sus componentes, al fin de alcanzar una mejora general en la economía y en la trayectoria de vida de los miembros del grupo (Prunier, 2017). En estos casos, los territorios rurales norteamericanos constituyen un espacio instrumental, de esfuerzo exclusivamente temporal y de acumulación de recursos destinados a la inversión para contar con mejores expectativas de vida y de trabajo en el nuevo territorio de asentamiento, sin que ello llegue a representar un lugar de arraigo a largo plazo.

A pesar de la lógica colectiva familiar que se encuentra debajo en esta circulación, de hecho, la elección no es profundamente autónoma, sino dictada por la necesidad económica y la imposibilidad de liberarse de las condiciones de pobreza actuales y para las generaciones futuras. Los costos sociales y afectivos que todos los miembros de las familias tienen que enfrentar son muy altos, y no siempre tienen buenos resultados, ya que nunca hay la seguridad de que la unión de la pareja se mantenga a la distancia. De hecho, las relaciones de pareja, así como entre padres e hijos, se ven profunda, y a veces indeleblemente, afectadas. Con respecto a esta realidad, presentamos los testimonios de una pareja, que ha vivido la experiencia de separación por muchos años y que nos ofrece los diferentes puntos de vista que entran en juego a nivel familiar en la dinámica de las ausencias repetidas y prolongadas de alguno de ellos. 
Esposa: Él se fue con un sacrificio bien grande de todos, porque yo me quedé con los niños y me iba al campo todos los días. Tenía que ir de la cinco de la mañana y regresar hasta en la tarde y los niños estaban solitos. Se iban a la escuela y la grande se encargaba de cuidarlos, tenía que cambiarlos, darles de comer, y yo llegaba y lavaba la ropa, todo a mano, y luego tenía que hacer comida, revisar si hicieron su tarea y si no, los pongo a que la hagan. Es que no era nada más ir al campo, tenía pendientes en la casa y muchas veces salía del campo y de ahí voy a la reunión de la escuela de mi hijo con pañuelo de trabajo... Eran cosas muy difíciles. Pero me armé de valor y saqué a mis hijos adelante y él también les hablaba por teléfono, dándoles orientación, porque luego están allá en la etapa de rebeldía...

Esposo: Yo siempre estaba ahí, que diario le hablaba y siempre le estaba dando consejos y atención y entonces es donde lo sacamos adelante. Pero también sufrieron ellos y puede ser que me echen la culpa. Porqué yo estoy seguro que en la escuela les hicieron burlas o que les pegaban y estas cosas ¿no? Y mi hijo no me contaba y entonces esto podría ser motivo de que lo pusieran a la droga. Por eso el niño también puso de su parte para que creciera bien. Porque cuando uno habla solo por teléfono ya no es igual. [...] Y yo que trabajaba diario y nomás vivía al día también. Fue sacrificio de todas partes pues, el mío, el suyo y de mis hijos también, porque estuvieron muchos años sin papá.

(Matrimonio de jornaleros, comunicación personal, 8 de julio de 2017, Valle de San Quintín).

Este transnacionalismo desde abajo, que tiene como centro de gravedad el Valle de San Quintín, no solo se expresa a través de los flujos de circulación regularizada e impulsada por las condiciones de necesidad descritas, sino también por un proceso de organización sindical de carácter interterritorial y de acción política dirigida tentativamente a una dimensión transnacional. De hecho, una parte del movimiento de jornaleros todavía activa y reunida en la Alianza de Organizaciones y el SINDJA realizó una caravana desde el Valle de San Quintín hacia Tijuana, en el marzo del año 2016, y otra posterior hasta la Ciudad de México, en marzo de 2017, para seguir reivindicando la mejora de las condiciones de vida y de trabajo agrícola, que lamentablemente siguen siendo muy parecidas desde el levantamiento de 2015. Uno de los momentos culminantes de la llamada Marcha de las dos Californias fue representado por el encuentro en la frontera de Tijuana entre jornaleros y activistas solidarios de México y Estados Unidos. Además, varios colectivos y organizaciones sociales dieron vida a una serie de iniciativas de boicoteo a las bayas de Driscoll's, desarrolladas frente a los grandes supermercados de varios lugares de ambos países, particularmente de Estados Unidos, en respuesta a las repetidas convocatorias del jDía de Acción Global para San Quintín!, lanzadas durante diferentes etapas desde las organizaciones del Valle (Ké Huelga Radio, 2016, 2017). Las ciudades involucradas en las acciones de boicoteo fueron las siguientes: New York, Chicago, Pittsburgh, Houston, Dallas, El Paso, Los Ángeles, San Diego y otras 13 ciudades de California, así como de Alaska, Australia y México. Además, 
la segunda caravana del marzo de 2017, denominada Caravana por un salario justo y una vida digna, llegó hasta la Ciudad de México, dando vida a una serie de iniciativas públicas en varios estados de este país y particularmente en Sonora, Sinaloa, Nayarit, Jalisco, Michoacán, Querétaro y el Estado de México. El fin de la caravana era construir y consolidar otras secciones del sindicato mencionado, que lograran incorporar al nuevo proceso de organización los jornaleros y jornaleras de varios territorios rurales mexicanos. Cerramos entonces con el testimonio de un representante sindical, que nos confirma claramente estas intenciones y acciones, políticas y sindicales, de aliento interterritorial y transnacional.

Los resultados del boicot ya se han estado viviendo y están mejorando un poco las condiciones de los trabajadores, y todo ha sido gracias a los diferentes colectivos y organizaciones que nos han ayudado a hacer el trabajo en diferentes supermercados. Lo hemos estado haciendo tanto en la Ciudad de México, como ahora vamos a trabajar en Michoacán, en Guanajuato, en Jalisco, donde también está Driscoll's y en Estados Unidos, por supuesto, donde se han formado comités de base que van a las tiendas y llevan folletos para concientizar a los consumidores sobre las condiciones en que viven los trabajadores. Entonces nosotros no vamos a parar hasta que realmente haya un contrato colectivo, donde se puedan garantizar realmente los derechos laborales de los trabajadores, hasta que tengan un salario justo y que se le respeten las prestaciones (Representante sindical, comunicación personal, 12 de julio de 2017, Valle de San Quintín).

\section{CONCLUSIONES}

En este texto se ha cuestionado el análisis de Portes, Guarnizo y Landolt (2003), que propone una distinción entre transnacionalismo desde abajo y desde arriba, priorizando la investigación del primer tipo de movilidad. En cambio, en este caso se ha tomado en cuenta la articulación de ambos procesos, analizando la relación existente entre las estrategias de movilidad del capital corporativo norteamericano y las de los jornaleros migrantes mexicanos. Se ha observado cómo esta interacción se manifiesta específicamente en el Valle de San Quintín, pero considerando el contexto territorial más amplio, que involucra diferentes áreas agrícolas de México y Estados Unidos.

Respecto al transnacionalismo desde arriba, se ha profundizado en el impacto en la estructura productiva local derivada de la acción de las compañías agroalimentarias norteamericanas. Se ha observado la organización territorial de estas últimas, con particular atención a las estrategias de reclutamiento y movilización espacio-temporal de la mano de obra entre diferentes áreas de México, así como a nivel transnacional mediante el uso de la visa temporal H-2A. Se ha observado cómo esta circulación laboral, manejada desde arriba, sirve fundamentalmente para satisfacer la demanda de mano de obra barata durante todo el ciclo estacional de los varios territorios productivos involucrados en la red corporativa. 
Considerando la gran variedad de grupos sociales que coinciden en este territorio crucero, se ha investigado tanto la dinámica circulatoria de los nuevos flujos de jornaleros, procedentes del centro y del sur del país, empleados temporalmente en el Valle, como la de los jornaleros ya asentados en las colonias y reclutados para trabajar estacionalmente en los campos de Estados Unidos, particularmente en California.

Entonces es posible concluir que en el caso estudiado la circulación laboral entre el Valle de San Quintín y otras áreas agrícolas de México y Estados Unidos, está directamente impulsada por la acción de las empresas agrícolas mexicanas y californianas. Estas últimas gestionan la movilidad de los empleados directa o indirectamente, a través de enganchadores informales y de agencias intermediarias oficiales que son facilitadas por la política migratoria del gobierno estadounidense. La estrategia de movilización de trabajadores temporales a nivel nacional y transnacional responde claramente a las necesidades del capital agroalimentario de disponer de mano de obra barata, flexible, y supuestamente no conflictiva, durante las temporadas de pico productivo en diferentes áreas rurales de la red corporativa de suministro.

Por otro lado, se han tomado en cuenta dos tipos de transnacionalismo desde abajo. De hecho, en el texto se ha profundizado cómo los jornaleros y las jornaleras migrantes se movilizan a nivel individual con la finalidad de mejorar las condiciones de vida de sus familias en el territorio mexicano de nuevo asentamiento. Pero también a nivel colectivo, promoviendo y realizando iniciativas políticas y sindicales de aliento nacional e internacional. La tensión interterritorial perseguida por los jornaleros y las jornaleras en ambos casos, constituye también una reacción a la globalización desde arriba, y a la pobreza provocada por las fuerzas económicas, siguiendo objetivos de bienestar familiar, intereses comunitarios y lucha de clase.

En conclusión, se ha observado cómo el Valle de San Quintín constituye un territorio crucero, en el cual se conjugan una globalización desde arriba y desde abajo. La continuidad transnacional entre el corredor agrícola del noroeste mexicano y el suroeste estadounidense soporta territorialmente la articulación de una relación compleja entre las estrategias de reproducción social y la organización política de los jornaleros y sus familias, por un lado y, por otro lado, las dinámicas organizativas del sector agroalimentario global, particularmente de las compañías freseras norteamericanas. 


\section{REFERENCIAS}

Andrew \& Williamson (2018). Follow our farms. San Quintin. Andrew \& Williamson Grupo [Página web corporativa]. Recuperado de http://www.andrew-williamson.com.

Aragón, O. A. (2015, 21 de marzo). Quisimos mostrarnos y mostrar nuestra fuerza. La Jornada. Recuperado de http:// https://www.jornada.com.mx/2015/03/21/politica/002n1pol

Bloomberg. (2018). Driscoll's Inc, Company Profile and News. Bloomberg Markets. Recuperado de http://www.bloomberg.com.

Camargo Martínez, A. (2015). Migración y cambio religioso: la construcción de "nuevas comunidades" de indígenas migrantes en la frontera noroeste del país (Tesis de maestría). Universidad Nacional Autónoma de México, Ciudad de México.

Castles, S., y Miller, M. J. (2004). La era de la migración: movimientos internacionales de población en el mundo moderno. Zacatecas: Universidad Autónoma de Zacatecas.

Ceceña, A. E. (2017). Chevron: la territorialidad capitalista en el límite. En A. E. Ceceña y R. Ornelas (Coords.), Chevron paradigma de la catástrofe civilizatoria, (pp. 7-22). México: Siglo XXI.

Corrado, A., De Castro, C., y Perrotta, D. (Eds). (2016). Migration and Agriculture: Mobility and Change in the Mediterranean Area. London: Routledge.

Dicken, P. (1998). Global shift: Transforming the world economy. New York: Guilford.

Driscoll's. (2018). Our practices. Where we grow. Recuperado de http://www.driscolls.com.

Durand, J. (2016). El subsistema migratorio mesoamericano. En C. Heredia Zubieta (Coord.), El Sistema migratorio mesoamericano, (pp. 23-59). México: El Colegio de la Frontera Norte.

Fresh Harvest. (2018). Fresh Harvest. H-2 ${ }^{\mathrm{a}}$ Labor Services. Recuperado de http://freshharvestusa.com.

Garrapa, A. M. (2019). Jornaleros agrícolas y corporaciones transnacionales en el Valle de San Quintín. Frontera Norte, 31. Recuperado de https://fronteranorte.colef.mx/index.php/fronteranorte/article/view/2018/1418

Gereffi, G., Humphrey, J. y Sturgeon, T. (2005). The Governance of Global Value Chains. Review of International Political Economy, 12(1), 78-104.

Izcara Palacios, S. P. (2015). Irregularidades en el reclutamiento de trabajadores agrícolas con visas H-2a en México. En M. J. Sánchez Gómez y S. M. Lara Flores (Coords.), Los programas de trabajadores agrícolas temporales, (pp. 207-233). México: Instituto de Investigaciones Sociales-Universidad Nacional Autónoma de México. 

$22 \begin{aligned} & \text { Globalización desde arriba y desde abajo en el Valle de San Quintín, en Oxnard y en otros territorios... } \\ & \text { Garrapa, A. M. }\end{aligned}$

Jaloma, E. C. (2016). El movimiento laboral-comunitario de los jornaleros del Valle de San Quintín. (Tesis de maestría). Facultad Latinoamericana de Ciencias Sociales, México.

Ké Huelga Radio (23 de noviembre de 2016). ¡Día de Acción Global para San Quintín! Recuperado de https://kehuelga.net/spip.php?article4777

Ké Huelga Radio (15 de marzo de 2017). La Caravana Nacional de Jornaleros por un Salario Justo y una Vida Digna continua su recorrido. Recuperado de https://kehuelga.net/spip.php?article4979

Krissman, F. (2005). Sin Coyote Ni Patrón: Why the 'Migrant Network' Fails to Explain International Migration. International Migration Review, 39(1), 4-44.

Lara Flores, S. M. (2003). La migración jornalera, antesala de las migraciones ilegales hacia Estados Unidos. México Indígena, 2(6), 6-12.

Lara Flores, S. M. (2010). Migraciones de trabajo y movilidad territorial. México: Porrúa.

Levitt, P., y Glick Schiller, N. (2004). Perspectivas internacionales sobre migración: conceptuar la simultaneidad. Migración y desarrollo, (3), 60-91.

Oficina Estatal de Información para el Desarrollo Rural Sustentable (OEIDRUS). (2016a). Serie Histórica. Fresa. Recuperado de http://www.oeidrusbc.gob.mx/oeidrus bca/pdf/participacion/agricola/FICHA\%20FRESA.pdf

(OEIDRUS). (2016b). Fresa 2016 Recuperado de http://www.oeidrusbc.gob.mx/oeidrus bca/fresa.php.

Palerm, J. V. (2014). An Inconvenient Persistence: Agribusiness and Awkward Workers in the United States and California. En L. A. Lorentzen (Coord.), Hidden Lives and Human Rights in the United States: Understanding the Controversies and Tragedies of Undocumented Immigration (pp. 55-119). Oxford: Prager.

Portes, A., Guarnizo, L. y Landolt, P. (2003). La globalización desde abajo: transnacionalismo inmigrante y desarrollo: la experiencia de Estados Unidos y América Latina. México: Facultad Latinoamericana de Ciencias Sociales.

Prunier, D. (2017). Repensar los retornos a través de los sistemas de movilidad en Centroamérica. El caso de Nicaragua. LiminaR, 15(1), 177-191.

Quesnel, A. (2010). El concepto de archipiélago: una aproximación al estudio de la movilidad de la población y la construcción de lugares y espacios de vida. En S. M. Lara Flores (Coord.), Los programas de trabajadores agrícolas temporales (19-22). México: Instituto de Investigaciones Sociales-Universidad Nacional Autónoma de México.

Reiter Affiiated Companies (RAC). (2018). Growers. International. Recuperado de http://www.berry.net/growers/international/

Sánchez Gómez, M. J. y Lara Flores, S. M. (Coords.). (2015). Los programas de trabajadores agrícolas temporales. México: México: Instituto de Investigaciones Sociales - Universidad Nacional Autónoma de México. 
Sassen, S. (1998) Globalization and its discontents: Essays on the new mobility of people and money. Nueva York: The New Press.

Secretaría de Agricultura y Desarrollo Rural (Sagarpa). (2015). Panorama general de "zona San Quintín", Baja California, 2015.

Sierra-Cascade Nursery. (2018). Locations. Recuperado de http://www.sierracascadenursery.com/locations.html.

Stephen, L. (2007). Transborder Lives: Indigenous Oaxacans in Mexico, California, and Oregon. Durham: Duke University Press.

Tarrius, A. (2007). La mundialización por abajo: el capitalismo nómada en el arco mediterráneo. Barcelona: Hacer.

Trigueros Lagarreta, P. (2015). La contratación de trabajadores agrícolas con visa H-2A. Del programa Bracero a la situación actual. En M. J. Sánchez Gómez y S. M. Lara Flores (Comps.), Los programas de trabajadores agrícolas temporales, (pp. 173-206). México: Instituto de Investigaciones Sociales - Universidad Nacional Autónoma de México.

Velasco, L., Zlolniski, C., y Coubès, M. L. (2014). De Jornaleros a Colonos: Residencia, Trabajo e Identidad en el Valle de San Quintín. Tijuana: El Colegio de la Frontera Norte. 